\title{
CONSIDERATION ABOUT COMPREHENSIVE DEVELOPMENT OF URBAN ECONOMY OF SHANXI PROVINCE OF CHINA
}

\author{
Li Changying and Wang Tianbao \\ Department of Industrial \& Commercial Management \\ Shanxi University of Fiance \& Economics \\ Tianyuan, Shanxi, P.R. of China \\ Strarsky@public.ty.sx.cn
}

\begin{abstract}
When the $21^{\text {st }}$ century is just around the corner, the knowledge economy is coming into being quietly. A common problem is posed to all professionals and trades of the whole society, which is how to forge ahead towards the knowledge economy times promptly. How to fit in with the needs of the market economy, how to integrate sci-tech with economic increase closely and how to transform sci-tech into productivity. Therefore the development of sci-tech and actual application and propagation of theoretical knowledge have become the heart of economic development. The urban economy development plays a decisive role for the development of the whole national economy. The developing history of the cities in the world has proved that quickening the tempo of urban economy development. Grasping the opportunity of development to strengthen urban comprehensive capabilities and heightening the level of urbanization are only road toward the modernization focusing on this central issue. This paper makes an evaluation for comprehensive economic capacities of twenty cities in Shanxi province with the propose of giving play to strong points of each city of city of itself and exploiting the potential factors for economic development of each city at the same time and providing scientific basis for urban developing programme of Shanxi Province adopting AHP method, an evaluation sequencing method with the combination of the quantitative with the qualitative, proposed by professor T. L. Saaty of Pittsburgh University of U.S.A.
\end{abstract}

